\title{
Article \\ Changes in Surface Characteristics of BOPP Foil after Treatment by Ambient Air Plasma Generated by Coplanar and Volume Dielectric Barrier Discharge
}

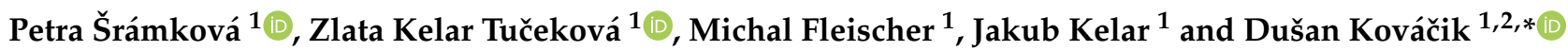 \\ 1 Department of Physical Electronics, CEPLANT—R\&D Centre for Plasma and Nanotechnology Surface \\ Modifications, Faculty of Science, Masaryk University, Kotlářská 2, 61137 Brno, Czech Republic; \\ petra.sramkova@mail.muni.cz (P.Š.); zlata.tucekova@mail.muni.cz (Z.K.T.); \\ michal.fleischer@mail.muni.cz (M.F.); jakub.kelar@mail.muni.cz (J.K.) \\ 2 Department of Experimental Physics, Faculty of Mathematics, Physics and Informatics, \\ Comenius University in Bratislava, Mlynská dolina, 84248 Bratislava, Slovakia \\ * Correspondence: dusan.kovacik@mail.muni.cz or kovacik@fmph.uniba.sk
}

check for updates

Citation: Šrámková, P.; Kelar Tučeková, Z.; Fleischer, M.; Kelar, J.; Kováčik, D. Changes in Surface Characteristics of BOPP Foil after Treatment by Ambient Air Plasma Generated by Coplanar and Volume Dielectric Barrier Discharge. Polymers 2021, 13, 4173. https://doi.org/ $10.3390 /$ polym 13234173

Academic Editor: Choon-Sang Park

Received: 24 October 2021

Accepted: 24 November 2021

Published: 29 November 2021

Publisher's Note: MDPI stays neutral with regard to jurisdictional claims in published maps and institutional affiliations.

Copyright: (c) 2021 by the authors. Licensee MDPI, Basel, Switzerland. This article is an open access article distributed under the terms and conditions of the Creative Commons Attribution (CC BY) license (https:/ / creativecommons.org/licenses/by/ $4.0 /)$.

\begin{abstract}
Biaxially oriented polypropylene (BOPP) is a highly transparent polymer defined by excellent mechanical and barrier properties applicable in the food packaging industry. However, its low surface free energy restricts its use in many industrial processes and needs to be improved. The presented study modifies a BOPP surface using two different atmospheric-pressure plasma sources operating in ambient air and capable of inline processing. The volume dielectric barrier discharge (VDBD) and diffuse coplanar surface barrier discharge (DCSBD) were applied to improve the wettability and adhesion of the 1-10 s treated surface. The changes in morphology and surface chemistry were analyzed by SEM, AFM, WCA/SFE, and XPS, and adhesion was evaluated by a peel force test. Comparing both plasma sources revealed their similar effect on surface wettability and incorporation of polar functional groups. Additionally, higher surface roughness in the case of VDBD treatment contributed to slightly more efficient adhesion in comparison to DCSBD. Although we achieved comparable results for both plasma sources in the term of enhanced surface wettability, degree of oxidation, and stability of induced changes, DCSBD had less effect on the surface deterioration than VDBD, where surface structuring caused an undesirable haze.
\end{abstract}

Keywords: BOPP foil; DCSBD; VDBD; surface wettability; adhesion; ageing; surface functionalization

\section{Introduction}

Biaxially oriented polypropylene (BOPP) is produced from melted polypropylene stretched in both transverse directions, producing molecular chains oriented in cross directions. Stretching into both directions ensures the significant improvement of its properties including enhanced barrier properties, increased toughness, and stiffness [1]. These properties, along with high transparency, make BOPP an excellent and cost-effective material in food [2,3] and tobacco packaging, but also in high energy density applications, e.g., capacitor production [4]. The BOPP's low surface free energy, however, hinders processes where good printability, adhesion, or improved wettability are required. The treatment by cold atmospheric-pressure plasma provides a popular solution for the surface activation of polymers and other thermally sensitive materials. However, the overturning and migration of these surface functional groups into a volume of material result in socalled hydrophobic recovery. This phenomenon often appears within days, and a loss of improved properties can be observed within a month on most BOPP substrates [5,6]. Thus, stable surface functionalization and adhesion improvement are required for industrially produced BOPP, often stored before further processing.

Dielectric barrier discharges (DBD) of various geometries are often used as the atmospheric-pressure nonequilibrium plasma sources for inline industrial applications. 
Volume DBD (VDBD), so-called "industrial corona", and diffuse coplanar surface barrier discharge (DCSBD) with a concavely curved electrode system suitable for roll-to-roll arrangement are often used for flexible large-area material treatment such as foils [7], paper, [8] and nonwoven textiles [9]. The treatment by atmospheric-pressure air DBD introduces polar functional groups providing hydrophilicity and an increase of surface free energy of the polymer surface. Industrial corona represents the most widely used plasma source in commercial use due to its simple operation in ambient air at the atmospheric pressure, fast speed, as well as short treatment times sufficient for material activation. However, corona discharge comprises hot filamentary microdischarges, which often cause thermally sensitive polymers' deterioration due to the perpendicular orientation of randomly distributed microdischarges towards the treated surface. In contrast to industrial corona, DCSBD enables generation of plasma consisting of microdischarges, where diffuse parts are intensified, while the filamentary elements are suppressed and parallel to the treated surface. The resulting diffuse plasma is thin, homogeneous, more effective, and less harmful to sensitive polymer materials.

Until now, the efficiency of surface activation of DCSBD plasma has been investigated on several polymer substrates. The high power density of such plasma ensured the improved wettability in the case of polyesters such as PEN [10], PET [11], PLA [12], or polycarbonate [13], as well as PMMA [14], even after $1 \mathrm{~s}$ of treatment. Moreover, our recent study considering the surface changes of PA 6 after DCSBD plasma treatment demonstrated the high potential of this technology to be part of industrial systems due to its very fast surface activation $(0.25 \mathrm{~s})$ and long-term preservation of the achieved properties [7]. The largest group of produced polymers worldwide represented by polyolefins were subjected to DCSBD plasma treatment in several studies [15-17]. However, the used exposure times were often too long (30-60 s) to meet industrial demand. Moreover, these studies were focused on changes in viscoelastic and tribological properties after plasma treatment. Despite BOPP being one of the most abundant polymers utilized in the packaging industry, plasma activation by DCSBD for a shorter treatment time (1-5 s) has only been reported once [18]. However, the achieved results were discussed very briefly, and the operation parameters of the DCSBD plasma source have been upgraded since the publishing of these data. There is lack of systematic study of the DCSBD plasma effect on the surface properties of BOPP substrate.

Here, we investigate and compare the efficiency of routinely used VDBD plasma represented by industrial corona systems and its possible alternative, namely DCSBD, for standard industrial roll-to-roll BOPP foil processing. The DCSBD in a concavely curved configuration of the electrode system is used for surface activation of BOPP foil, and changes in surface characteristics are compared with those achieved after treatment by VDBD. Morphological changes, surface wettability, adhesion, chemical composition, and the stability of the achieved properties are investigated.

\section{Materials and Methods}

\subsection{Material}

Biaxially oriented polypropylene (BOPP) cigarette foil used for the experiments was provided by Chemosvit folie s.r.o., Svit, Slovakia. BOPP foil with a thickness of $25 \mu \mathrm{m}$ and a square weight of $22.8 \mathrm{~g} \mathrm{~m}^{-2}$ was delivered in the form of a roll. BOPP foil of a width of $25 \mathrm{~cm}$ was treated by plasma and cut to the required size for a particular analysis.

\subsection{Plasma Treatment}

The plasma treatment was carried out by two different dielectric barrier discharges generating nonequilibrium "cold" atmospheric plasma. Diffuse coplanar surface barrier discharge (DCSBD) in concavely curved configuration of the electrode system operating at atmospheric pressure in ambient air produces particularly diffuse "cold" plasma, while volume dielectric barrier discharge (VDBD) generates "cold" plasma solely in filamentary mode. A schematic description of both electrode systems is depicted in Figure 1. Detailed 
technical specifications of both plasma sources were discussed elsewhere [7]. Regarding DCSBD, the sample was attached to the roller at a distance of $0.3 \mathrm{~mm}$ from the electrode system. Input power was adjusted at a value of $400 \mathrm{~W}$ (the frequency of $\sim 15 \mathrm{kHz}$ ), and the treatment speed was set at a constant value of $4.8 \mathrm{~m} \mathrm{~min}^{-1}$ corresponding to a treatment time of $1 \mathrm{~s}$. Samples were exposed to plasma for 1,3,5, and $10 \mathrm{~s}$ applying the corresponding rotation cycles. VDBD operated in the following conditions: the input power was set to the value of $380 \mathrm{~W}$, corresponding to the same square power density of $2.5 \mathrm{~W} \mathrm{~cm}^{-2}$ as the plasma produced by DCSBD. The average speed of cylinder rotation was $18 \mathrm{~m} \mathrm{~min}^{-1}$, and the distance between the sample and high-voltage electrodes was set to the value of $1 \mathrm{~mm}$. Treated samples were stored in Petri dishes under the following laboratory conditions: temperature $=23^{\circ} \mathrm{C}$ and humidity $=40 \%$.

a)

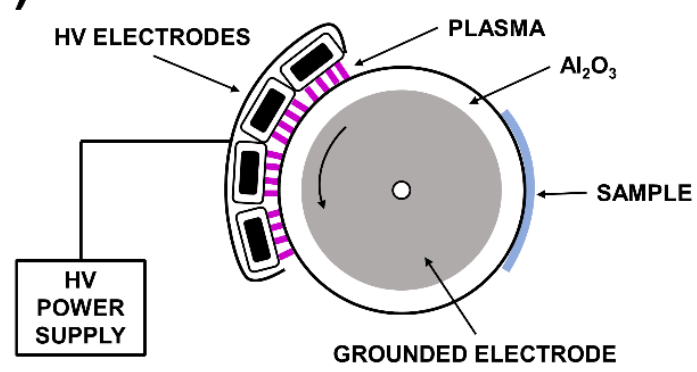

b)

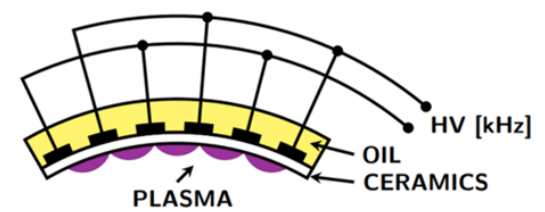

Figure 1. Schematic representation of used plasma sources: (a) VDBD electrode system and (b) concavely curved DCSBD electrode system.

\subsection{Analytical Methods}

Imaging of surface morphology was performed using a Scanning Electron Microscope Mira3 (Tescan, Brno, Czech Republic) with a maximum resolution of $1 \mathrm{~nm}$ and a maximum magnification of $1,000,000$. The detector of secondary electrons and accelerating voltage of $15 \mathrm{kV}$ was used. The surface morphology analysis was conducted with magnification up to 50,000 . To prevent charging of the sample, the BOPP foil surface was coated with $20 \mathrm{~nm}$ of the $\mathrm{Au} / \mathrm{Pd}$ layer by sputter coater Quorum Q150R-ES (Quorum Technologies, Lewes, United Kingdom). The changes in surface roughness were measured using Atomic Force Microscope NTEGRA Prima (NT-MDT, Moscow, Russia) in a semi-contact mode. The Root Mean Square (RMS) roughness was estimated from the area $5 \times 5 \mathrm{~mm}^{2}$ with resolution $512 \times 512 \mathrm{px}^{2}$ and scanning frequency of $1 \mathrm{~Hz}$.

The contact angles (CA) of water, diiodomethane, and ethylene glycol were measured by a See (Surface Energy Evaluation) System analyzer (Advex Instruments, Brno, Czech Republic) using sessile droplets with volume $1 \mu \mathrm{L}$. The resulting values of $\mathrm{CA}$ were calculated as an average value from at least ten droplets taken at the BOPP surface exposed to plasma at different treatment conditions. Surface free energy (SFE) values were calculated using the Owens-Wendt regression model [19].

XPS analysis was performed by the spectrometer Axis Supra (Kratos Analytical Ltd., Manchester, United Kingdom) using monochromated AlK $\alpha$ radiation of energy of $1486.6 \mathrm{eV}$. Emitted photoelectrons were collected by an analyzer from a sample area of size $300 \times 700 \mu \mathrm{m}^{2}$ perpendicular to the sample surface. Because the samples are insulators, it was necessary to use a charge neutralizer electron source to compensate for sample charging during analysis. All spectra obtained under such conditions are shifted from the base position by a few $\mathrm{eV}$ to the lower binding energies. Therefore, it was necessary to perform energy calibration by shifting spectra according to a reference peak. Survey spectra were collected using an analyzer pass energy of $80 \mathrm{eV}$ and high-resolution spectra for pass energy of $20 \mathrm{eV}$. The step size of the high-resolution spectra was $0.1 \mathrm{eV}$. Spectra calibration, processing, and fitting routines were completed using CASA software (trial version CasaXPS 2.3.16, CASA international nv, Olen, Belgium). 
Static material testing machine Texture Analyser TA.XT plusC (Stable Micro Systems, Surrey, United Kingdom) was used for peel force measurements [20,21]. The $90^{\circ}$ tape peel test for evaluating adhesion on plasma-treated BOPP foils was carried out using a peel fixture called "Rotating German Wheel" for continuous peeling off of the adhesive tape from the sample. Measurement was performed according to the FINAT test method no. 2. (a $90^{\circ}$ peel adhesion test). The loading speed was set to the value of $10 \mathrm{~mm} \mathrm{~min}^{-1}$, and the load cell with a $50 \mathrm{~N}$ range was used for adhesion measurements. The sample was prepared by sticking a $19 \mathrm{~mm}$ wide $-\mathrm{Scotch}^{\mathrm{TM}}$ Magic $^{\mathrm{TM}}$ adhesive tape (3M, St. Paul, MN, USA) on the BOPP foil sample and ensuring 10 passes over a taped area with a rolling pin. The evaluation of measured peel force was in a range from $20 \mathrm{~mm}$ to $70 \mathrm{~mm}$, whereas measurement values for the initial length of $20 \mathrm{~mm}$ were discarded. The average peel force was calculated from 3 to 5 tests of samples treated in the same conditions [7].

\section{Results}

\subsection{Surface Morphology}

Physicochemical interactions at the plasma-polymer interface can induce the etching of the polymer surface, which primarily affects the morphology of the surface. Therefore, morphological changes were monitored by scanning electron microscopy (SEM) and atomic force microscopy (AFM). The SEM image of the untreated BOPP foil surface (REF) depicted in Figure 2 demonstrates its very smooth and homogeneous nature at the micrometer scale. Lower plasma exposure times ( 1 and $3 \mathrm{~s}$ ) in the case of DCSBD did not affect the surface morphology. After $5 \mathrm{~s}$ as well as $10 \mathrm{~s}$ of plasma treatment, we observed the formation of droplet-like structures with a diameter around 50-100 nm. Compared to the moderate effect of DCSBD on surface roughening, VDBD had a much more pronounced effect on the surface morphology. One second of plasma treatment showed mild structuring (Figure 2e) of surface, but a longer treatment time induced formation of droplet-like structures. However, the formed droplets had a size of around $200 \mathrm{~nm}$ ( 3 and $5 \mathrm{~s}$ in Figure 2f,g) or even larger (10 s in Figure 2h). Our results from SEM were quite different from other studies. Shekargoftar et al. [11] treated the PP/Al/PET-based laminated foil by DCSBD as well as the VDBD plasma source. The authors achieved the droplet-like structure at the PP side of the foil, after $3 \mathrm{~s}$ of plasma treatment by both plasma sources. Additionally, the droplets were enlarged due to merging after DCSBD treatment (up to $5 \mu \mathrm{m}$ in diameter) in comparison to VDBD. A recent study by Janík et al. [16] demonstrated the formation of very similar structures after the treatment of PP specimens by coplanar DCSBD. However, in both mentioned studies, the size of droplets formed after treatment by DCSBD plasma was around $1-5 \mu \mathrm{m}$, which is much higher than our droplets possessing size in nanometers. In the case of PP/Al/PET-based laminated foil [11], these differences could be caused by the presence of a conductive Al layer, causing the parasitic microfilaments to burn perpendicular to the foil during DCSBD treatment, and also by the different nature of the used PP substrate, which relates to the manufacturing process as well as to the ratio of amorphous and crystalline regions on the surface. The degree of crystallinity and arrangement of crystalline and amorphous segments in polymer determine the resulting structuring of the surface after plasma treatment [22]. Plasma etching leads to the faster degradation of the amorphous phase in the BOPP structure, while crystalline regions become revealed, which defines the resulting roughening.

The AFM images are depicted in Figure 3 with inserted values of RMS roughness. The results from the AFM measurement revealed the low degree of roughness of raw BOPP foil with a value of $5.0 \mathrm{~nm}$ comparable to other papers. Strobel et al. [23] observed RMS roughness values in the range $2.3-4.3 \mathrm{~nm}$ for various types of BOPP differing in orientation. Another paper by Chen et al. [24] measured RMS roughness of $3.8 \mathrm{~nm}$, and Darvish et al. [25] published roughness of BOPP film with a value of $6.8 \mathrm{~nm}$. Exposure to DCSBD only slightly influenced the RMS values, but the AFM images show negligible surface topography changes. Plasma treatment during the first $3 \mathrm{~s}$ (Figure 3a,b) induced the formation of hole-like structures even though the roughness seemingly did not change 
in comparison to reference. However, the formed holes possessed very low depth, which supported small differences in roughness. Longer treatment times (Figure 3c,d) resulted in a decrease in roughness, but values varied in the range of $4-4.6 \mathrm{~nm}$, which represented a negligible change. In accordance with the SEM images, plasma treatment by VDBD induced more pronounced changes in topography and roughness. With increasing plasma exposure times, roughness gradually increased (Figure $3 \mathrm{e}-\mathrm{h}$ ) to the highest value of $24.9 \mathrm{~nm}$ after $10 \mathrm{~s}$ of VDBD plasma treatment. Wang et al. [26] used atmospheric-pressure dielectric barrier discharge to generate the air plasma for PP treatment and achieved roughness values from $15.3 \mathrm{~nm}$ to $55.3 \mathrm{~nm}$ depending on different treatment conditions. Oravcová et al. [18] monitored the effect of atmospheric-pressure plasma generated by DCSBD on surface characteristics of monoaxially oriented PP. They achieved a roughness increase to value $24 \mathrm{~nm}$ after $5 \mathrm{~s}$ of plasma treatment. However, the BOPP in our case cannot be directly compared with other PP substrates, because the manufacturing by stretching in two directions provides different properties than other types of PP. BOPP was treated by DBD in the study of Chen et al. [24], where they observed a change in roughness from the initial $3.8 \mathrm{~nm}$ to $7.2 \mathrm{~nm}$ after $3 \mathrm{~s}$ of treatment which corresponds to our value after $1 \mathrm{~s}$ of VDBD treatment.
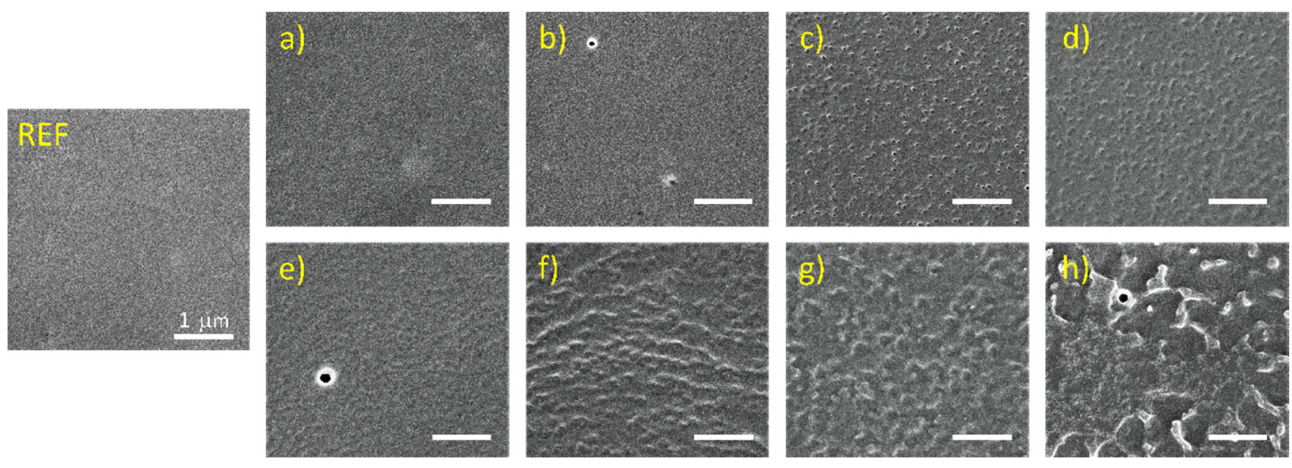

Figure 2. SEM images of BOPP foil treated by plasma at the different experimental conditions: (a-d) DCSBD at $1 \mathrm{~s}, 3 \mathrm{~s}, 5 \mathrm{~s}$, and $10 \mathrm{~s}$ and (e-h) VDBD at $1 \mathrm{~s}, 3 \mathrm{~s}, 5 \mathrm{~s}$, and $10 \mathrm{~s}$.

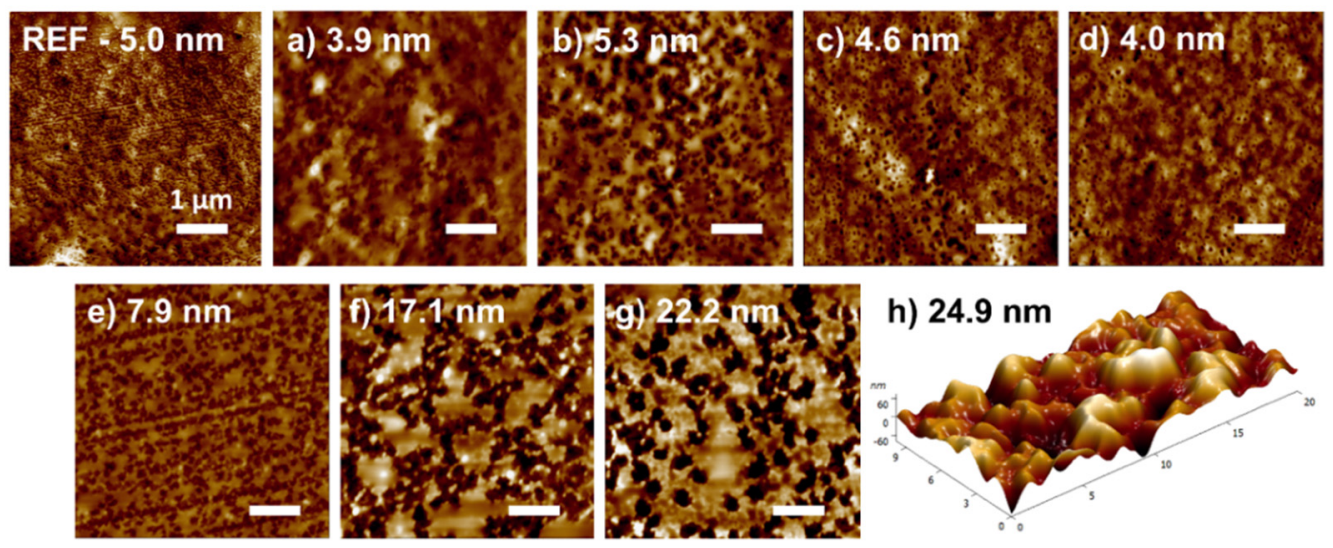

Figure 3. AFM images of BOPP foil treated by plasma at the different experimental conditions: (a-d) DCSBD at $1 \mathrm{~s}, 3 \mathrm{~s}, 5 \mathrm{~s}$, and $10 \mathrm{~s}$ and $(\mathbf{e}-\mathbf{h})$ VDBD at $1 \mathrm{~s}, 3 \mathrm{~s}, 5 \mathrm{~s}$, and $10 \mathrm{~s}$. Values of roughness are inserted in the appropriate pictures.

Moreover, morphological changes monitored on the BOPP surface treated by VDBD induced changes in the optical properties of BOPP foil. The fully transparent foil lost its transparency after $3 \mathrm{~s}$ of exposure, and we monitored the formed haze, which intensified with the plasma treatment time. Haze is caused by light scattering, which can originate from the bulk of the material as well as from its surface. Since the DCBSD treated samples did not change their optical properties, the haze visible on VDBD treated samples is 
probably connected to the creation of hole-like structures (Figure $3 \mathrm{f}-\mathrm{h}$ ), which can cause light scattering. The most probable explanation for such structures is the penetration of filamentary plasma through the upper layer of the surface. Moreover, the generated droplet-like structures with sizes between 0.2 and $1 \mu \mathrm{m}$ corroborated these findings. Surface structures possessing dimensions similar to the visible light wavelength induce Mie scattering resulting in the milky appearance of the plasma treated foil [27].

\subsection{Wettability and Ageing Study}

Regarding the hydrophobic nature of polypropylene, the wettability of pristine BOPP film is very low, which agrees with the water contact angle (WCA) value of $104.8 \pm 0.4^{\circ}$ and surface free energy (SFE) value of $26.8 \mathrm{~mJ} \mathrm{~m}^{-2}$. The development of WCA after plasma treatment is depicted in Figure $4 a$, and changes in SFE are shown in Figure $4 \mathrm{~b}$. The treatment of BOPP surface by both plasma sources, coplanar and volume DBD, improved the wettability already after $1 \mathrm{~s}$ of plasma exposure. In the case of DCSBD, increased plasma exposure time resulted in gradually decreased WCA until achieving the lowest value $\left(52.1 \pm 0.5^{\circ}\right)$ after $10 \mathrm{~s}$ of treatment. In comparison, VDBD resulted in decreasing WCA to $68.9 \pm 0.8^{\circ}$ already after $1 \mathrm{~s}$. The lowest WCA was observed after $3 \mathrm{~s}$ of treatment $\left(66.5 \pm 3.5^{\circ}\right)$, followed by an increase in WCA with prolonged plasma exposure time. The rising of WCA after high plasma exposure times (10 s) can be explained by roughening of the surface after the VDBD treatment caused by etching. Although, etching usually occurs at higher exposure times (order of minutes), in the case of destructive VDBD filamentary plasma, it is possible that $10 \mathrm{~s}$ is sufficient for surface roughening and undesirable hydrophobization. The study on the plasma treatment of selected polyolefins revealed how an appropriate combination of microscale features on the surface with plasma-etched nanoscale roughness can regulate the wettability of the substrate [28].

a)

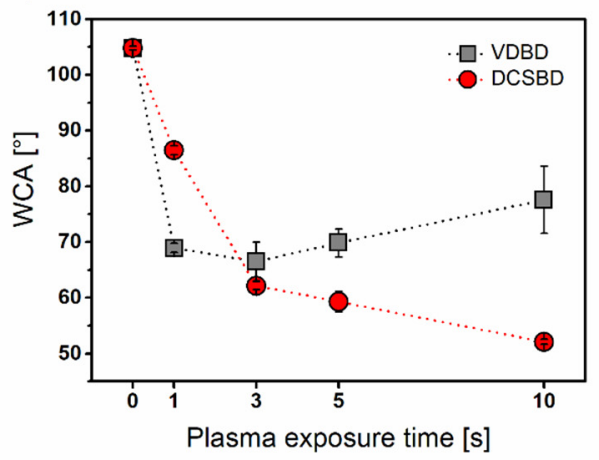

b)

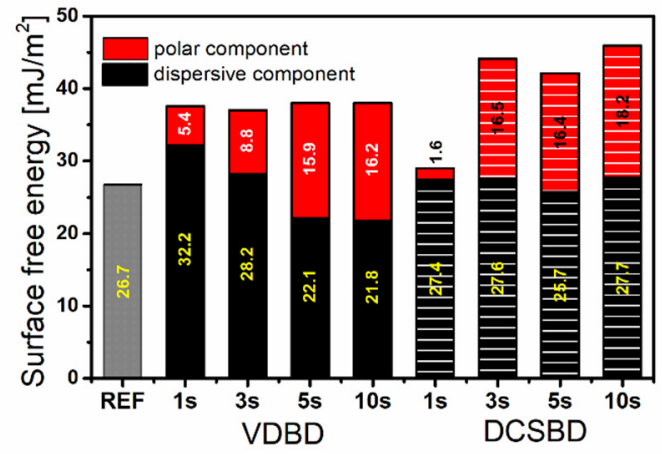

Figure 4. Graphs of WCA and SFE measurements: (a) WCA values measured immediately after plasma exposure of BOPP foil by VDBD (grey square) and DCSBD (red circle) for different plasma treatment times (1, 3, 5, and $10 \mathrm{~s}$ ); (b) comparison of surface free energy (SFE) of BOPP foil treated by VDBD and DCSBD with inserted values of polar and dispersive component of SFE.

The SFE of pristine BOPP mainly comprised a dispersive component representing $26.7 \mathrm{~mJ} \mathrm{~m}^{-2}$ from $26.8 \mathrm{~mJ} \mathrm{~m}^{-2}$ of total SFE value. The absence of a polar component corresponds to the fully hydrocarbon structure of BOPP. Oxidation of the BOPP surface induced by plasma treatment resulted in an increase in SFE for both plasma sources (Figure 4b). Treatment by VDBD in all exposure times led to similar SFE values of $37-38 \mathrm{~mJ} \mathrm{~m}^{-2}$. Additionally, the polar component gradually rose with the increased plasma exposure time from $5.4 \mathrm{~mJ} \mathrm{~m}^{-2}$ to $16.2 \mathrm{~mJ} \mathrm{~m}^{-2}$ proving the high effect of atmospheric cold plasma on the polar part of SFE. The increasing polar component represents the formation of polar functional groups on treated BOPP due to the presence of oxygen and nitrogen in air. The air humidity and hydrogen abstraction from the polymer chain allows the formation of hydroxyl radicals in the gas phase and causes the formation of free radicals [29]. The free radicals provide further reaction of the activated surface with reactive oxygen and nitrogen species present in air plasma. The change in dispersive component is related mostly to the 
presence of nonpolar functional groups. Furthermore, the changes in surface morphology also contribute to the dispersive component. The increase in the dispersive component of SFE after the short VDBD plasma treatment was observed on PP in Shekargoftar et al. [11], followed by a decrease to the reference value after $5 \mathrm{~s}$.

In comparison, DCSBD was more efficient in surface activation showing higher values of SFE (42-45.9 mJ m $\mathrm{m}^{-2}$ ) except for the exposure time of $1 \mathrm{~s}$ where only $29 \mathrm{~mJ} \mathrm{~m}^{-2}$ was achieved. Moreover, atmospheric plasma generated by DCSBD had a more pronounced impact on the polar part of SFE, which reached values in the range of $16.4-18.2 \mathrm{~mJ} \mathrm{~m}^{-2}$. The polar component of surface energy represents the highest contribution to the total value of SFE. The increase in and further stabilization of the polar component of SFE were achieved after $3 \mathrm{~s}$ of DCSBD treatment. The dispersive component altered negligibly after the DCSBD treatment reflecting the small changes in surface morphology.

Enhancement of surface wettability after the plasma treatment is not fully permanent. The rate of hydrophobic recovery of the activated surface depends on many factors, such as the chemical nature of the substrate, storage conditions, as well as the used plasma source. Monitoring the WCA changes over time represents a great tool for investigating the stability of plasma-induced changes. WCA development during the 30 days of storage under laboratory conditions is illustrated in Figure 5. Surprisingly, the ageing effect for the samples treated by VDBD was very slow. WCAs measured on BOPP sample exposed to VDBD plasma for $1 \mathrm{~s}$ maintained the stable contact angle during the whole monitoring time. Similar behavior was observed by Borcia et al. [30] for HDPE treated by filamentary type of DBD. Compared to other hydrocarbon polymers (polystyrene and polymethylpentene), the HDPE surface stayed stable for two weeks. On the contrary, the BOPP sample exposed to DCSBD for $1 \mathrm{~s}$ recovered to the reference WCA value within the first $24 \mathrm{~h}$. Further, VDBD samples treated for $3 \mathrm{~s}$ and longer experienced slight hydrophobic recovery during the first 3 days of storage. After a month of storage, all VDBD samples remained hydrophilic. Similar effects were observed in the case of 3-10 s DCSBD treated samples. However, after the month of storage, the WCA values were lower for DCSBD than for VDBD treated samples.

\section{a) VDBD}

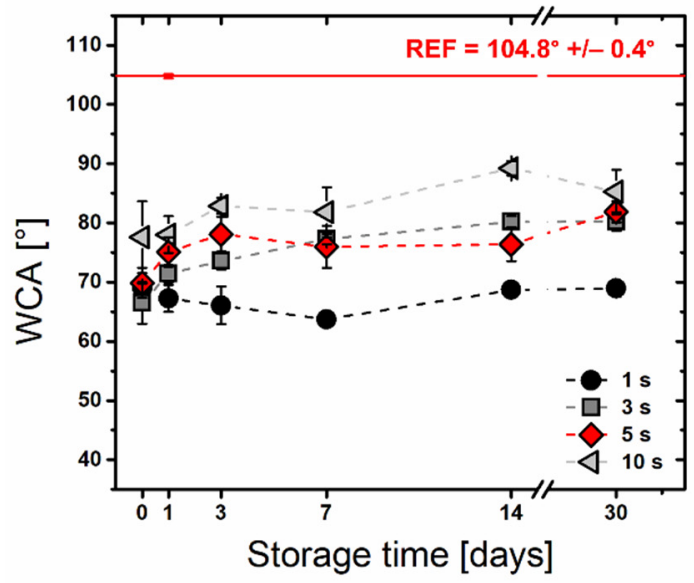

\section{b) DCSBD}

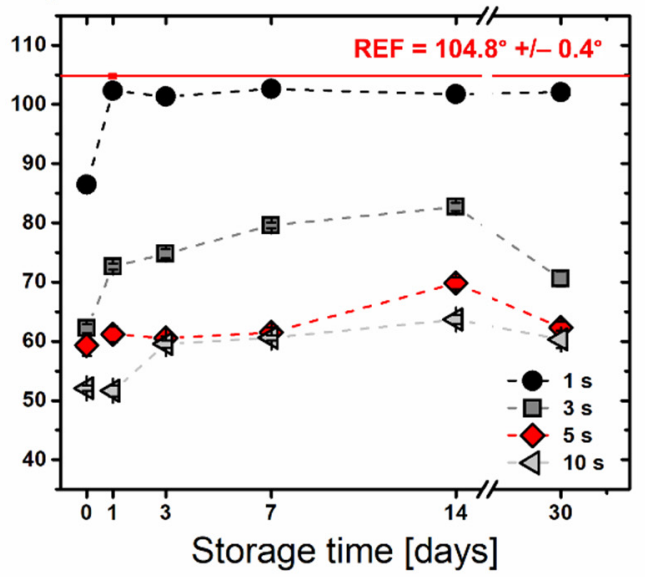

Figure 5. WCA development during the storage of BOPP foils under laboratory conditions: WCA values dependent on storage time after the plasma treatment by (a) VDBD and (b) DCSBD.

\subsection{Peel Force}

The peel force improvement of the BOPP surface was observed after the treatment by both plasma sources (Figure 6). The reference value of $0.75 \mathrm{~N} \mathrm{~cm}^{-1}$ almost tripled after $1 \mathrm{~s}$ of VDBD and rose with increased treatment time. The high error values of peel force are often related to the nonuniform treatment of large-area surfaces by VDBD [31]. In our case, these variations could be the results of surface topography and roughness changes, which 
also contributed to higher peel force values for VDBD compared to less invasive diffuse plasma generated by DCSBD. However, the adhesion improvement of the BOPP surface corresponds with the polar component increase after VDBD plasma treatment, which was also observed for DCSBD treated samples. After $3 \mathrm{~s}$ of treatment by DCSBD, the peel force value stabilized, and it did not change with prolonged treatment. In contrast, Bhat et al. [32] observed a decrease in peel force during the first $60 \mathrm{~s}$ of RF plasma exposure. The expected increase occurred after plasma exposure time on the order of minutes. The postponed effect of plasma treatment was explained as plasma cleaning of commercially manufactured and contaminated BOPP surface prior to surface modification. As a result, the time needed for BOPP adhesion improvement in the case of RF plasma was significantly longer than in our case. These results indicate the relation of BOPP adhesive properties with the formation of polar functional groups and surface roughness $[5,32,33]$.

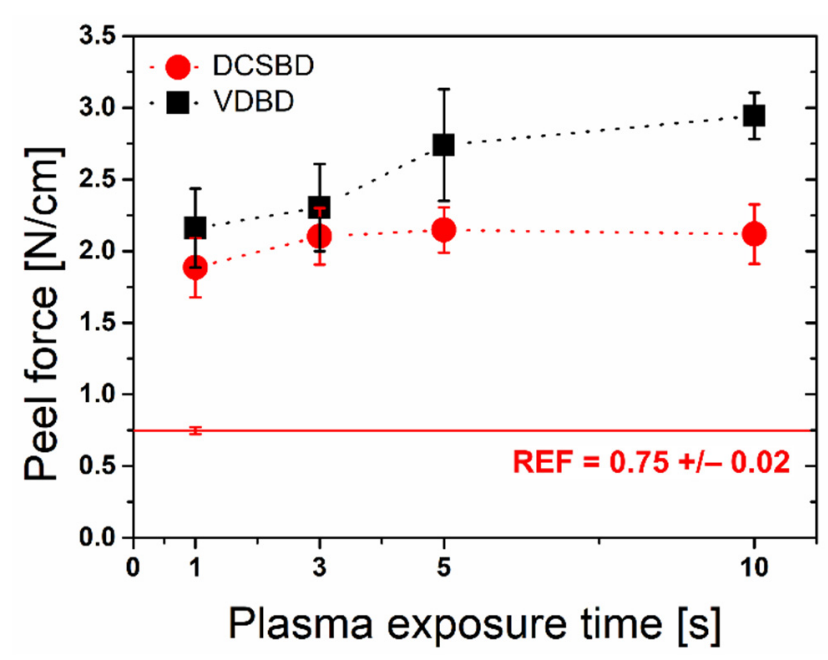

Figure 6. Development of the peel force of the BOPP surface after plasma treatment.

\subsection{Surface Chemical Analysis}

Improved wettability after plasma treatment indicates increased hydrophilicity of the BOPP surface related to the formation of polar functional groups. Chemical changes on the plasma-treated samples were monitored by X-ray photoelectron spectroscopy (XPS). The atomic composition of untreated and plasma-treated BOPP foil observed by XPS is summarized in Table 1 . The untreated BOPP foil contained $95 \%$ carbon and $5 \%$ oxygen, which is in good accordance with other studies using various PP substrates [15,26,34,35]. The presence of oxygen on the raw BOPP surface suggests organic contamination or lowlevel surface oxidation. The treatment by both plasma sources induced an increase in oxygen concentration to $20 \%$ after $1 \mathrm{~s}$. Further increasing plasma exposure time led to the higher oxygen content with the highest level at $28 \%$ for the sample treated by VDBD at $10 \mathrm{~s}$. Otherwise, achieved oxygen contents were comparable for both plasma sources, reflecting the similar level of surface oxidation for diffuse and filamentary plasma. Compared to the study of Saranko et al. [15], where they observed $23.6 \%$ of oxygen content after $60 \mathrm{~s}$ of plasma treatment by DCSBD (pristine $~ 5.3 \%$ ), we proved that a few seconds of plasma treatment were sufficient for surface activation of hydrophobic polymers. Despite the use of ambient air as a working gas for experiments, nitrogen atoms appeared at the BOPP surface in a negligible concentration (1-2.2\%). A similar outcome was also monitored in other studies [29,36,37]. Dorai and Kushner explained the poor incorporation of $\mathrm{N}$-based functional groups due to the low reactivity of $\mathrm{N}$ atoms towards the plasma-treated PP surface. They described in detail the mechanism of PP surface functionalization under the industrial corona treatment in humid air resulting in the formation of alcohol, carbonyl, carboxy, and peroxy groups. 
Table 1. The atomic concentration and relative area of $\mathrm{C} 1 \mathrm{~s}$ chemical bonds of the BOPP surface analyzed by XPS measurement after treatment by DCSBD and VDBD plasma sources.

\begin{tabular}{|c|c|c|c|c|c|c|c|c|c|}
\hline & & Con & om & 1 & & Functi & al Groups & oncentrati & {$[\%]^{2}$} \\
\hline & & C & O & $\mathbf{N}$ & O/C Ratio & $\begin{array}{l}\mathrm{C}-\mathrm{C} / \mathrm{C}-\mathrm{H} \\
284.8 \mathrm{eV}\end{array}$ & $\begin{array}{c}\mathrm{C}-\mathrm{O} \\
285.9 \mathrm{eV}\end{array}$ & $\begin{array}{c}\mathrm{C}=\mathrm{O} \\
287.5 \mathrm{eV}\end{array}$ & $\begin{array}{c}\mathrm{O}-\mathrm{C}=\mathrm{O} \\
289.3 \mathrm{eV}\end{array}$ \\
\hline & REF & 95 & 5 & - & 0.05 & 94.2 & 5.8 & - & - \\
\hline & $1 \mathrm{~s}$ & 80 & 20 & $<1$ & 0.25 & 76.5 & 15.1 & 6.7 & 1.7 \\
\hline 0 & $3 \mathrm{~s}$ & 74 & 24 & 1.8 & 0.33 & 71.5 & 14.3 & 8.1 & 6.1 \\
\hline Uु & $5 \mathrm{~s}$ & 73 & 24 & 2.2 & 0.33 & 69.2 & 14.2 & 9.1 & 7.5 \\
\hline D & $10 \mathrm{~s}$ & 72 & 26 & 1.7 & 0.36 & 65.8 & 15.9 & 9.8 & 8.6 \\
\hline & $1 \mathrm{~s}$ & 79 & 20 & $<1$ & 0.26 & 73.7 & 14.0 & 7.1 & 5.3 \\
\hline 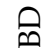 & $3 s$ & 74 & 25 & 1.0 & 0.33 & 66.5 & 15.3 & 9.3 & 8.9 \\
\hline$\dot{\rho}$ & $5 \mathrm{~s}$ & 73 & 26 & 1.1 & 0.35 & 65.7 & 15.2 & 9.1 & 10.0 \\
\hline & $10 \mathrm{~s}$ & 71 & 28 & 1.2 & 0.39 & 62.3 & 15.3 & 9.6 & 12.9 \\
\hline
\end{tabular}

${ }^{1}$ Estimated from survey spectra. ${ }^{2}$ Estimated by deconvolution of C1s high-resolution spectra.

The deconvolution of $\mathrm{C} 1 \mathrm{~s}$ high-resolution spectrum of the reference sample consisted dominantly of $\mathrm{C}-\mathrm{C} / \mathrm{C}-\mathrm{H}$ bonds typical for a BOPP structure. Further, the residual quantity of the $\mathrm{C}-\mathrm{O}$ bonds originating from the manufacturing process was revealed. After the air plasma treatment, the concentration of $\mathrm{C}-\mathrm{O}$ bonds increased from an initial $6 \%$ and saturated at a value of approx. $15 \%$ for all used plasma treatment conditions. This can be explained by quenching of alkoxy radicals formed at the PP backbone after $\mathrm{H}$-abstraction, which results in the formation of $\mathrm{C}-\mathrm{O}$ groups. Other alkoxy radicals undergo the $\beta$-scission to yield $\mathrm{C}=\mathrm{O}$ groups. In our study, the $\mathrm{C}=\mathrm{O}$ and $\mathrm{O}-\mathrm{C}=\mathrm{O}$ bonds were formed right after the short plasma treatment by both plasma sources, and their concentrations increased with time. The level of $\mathrm{C}=\mathrm{O}$ bonds was slightly higher for samples treated by VDBD as well as the amount of $\mathrm{O}-\mathrm{C}=\mathrm{O}$ groups. The $\mathrm{O}-\mathrm{C}=\mathrm{O}$ groups achieved higher values for all plasma exposure times in the case of VDBD treatment. The air humidity also plays a great role in the concentration of formed functional groups [29]. However, investigating the influence of relative humidity on chemical changes after plasma treatment of BOPP surface was outside of the scope of this study. Borcia et al. [30] observed comparable chemical changes on the surface of hydrocarbon polymers after treatment by air VDBD plasma having similar operating conditions as our experiment. Oxidation of poly(ethylene) (PE) was more efficient than in the case of branched poly(methylpentene) (PMP) in terms of functional groups concentration. In our case, after the corresponding treatment time, we observed $14-15.3 \%$ of alcohol groups presenting the lower level compared to $18-19.2 \%$ for $\mathrm{PE}$ and PMP in the mentioned study. However, the achieved concentrations of carbonyl and carboxyl functionalities in our experiment were between PE and PMP. Considering the structure of monomer units in particular polymers (PE, PMP and PP), oxidation of $\mathrm{PE}$ consisting fully of $-\mathrm{CH}_{2}-$ bonds was faster than in the case of branched PMP and PP. According to the proposed mechanism for hydrocarbon oxidation in plasma [29], initial $\mathrm{H}$-abstraction from the surface depends on its position in the polymer backbone. Although the probability of abstractions follows the order: $\mathrm{H}_{\text {tert }}>\mathrm{H}_{\mathrm{sec}}>\mathrm{H}_{\text {pri, }}$, the most reactive tertiary $\mathrm{H}$ present in $\mathrm{PP}$ and PMP is hindered by less reactive $\mathrm{H}$ from $-\mathrm{CH}_{3}$ groups. This could be the reason for the more rapid oxidation of PE consisting solely of secondary $\mathrm{H}$.

The polar functional groups contribute to the polar component of SFE and increased wettability of the BOPP surface. However, the respective XPS data do not reflect the corresponding WCA results. The similar behavior monitored by Borcia et al. [30] explains the discrepancies between WCA and XPS results based on the different effective depths analyzed by these two techniques.

Additionally, XPS analysis was employed to monitor the stability of surface oxidation during the storage of samples under laboratory conditions. In Figure 7, the $\mathrm{O} / \mathrm{C}$ ratio is plotted against the storage time. Ageing curves of BOPP samples treated by DCSBD for 
$3-10 \mathrm{~s}$ follow a similar decreasing trend and end up around value 0.22 . In general, the $\mathrm{O} / \mathrm{C}$ ratio values achieved right after the treatment decreased by $31-39 \%$ after 28 days of storage. In comparison to these samples, the sample treated for $1 \mathrm{~s}$ possessing the lowest oxidation exhibited a less steep trend of ageing (20\%). The O/C ratio of VDBD treated samples after 28 days of storage were very similar to those achieved in the case of DCSBD (the decrease by $30-34 \%$ ). Leroux et al. [36] investigated the development of the $\mathrm{O} / \mathrm{C}$ ratio on the PP surface treated by DBD plasma during the 30 days of ageing. Surprisingly the ageing process was slower than in our case (17-23\%); however, they observed much lower values of $\mathrm{O} / \mathrm{C}$ ratios $(0.12-0.16)$. A similar trend of $\mathrm{O} / \mathrm{C}$ ratio decrease during ageing was also observed for oxygen containing functional groups proportional to $\mathrm{C}-\mathrm{C}$ bonds.

\section{a) DCSBD}

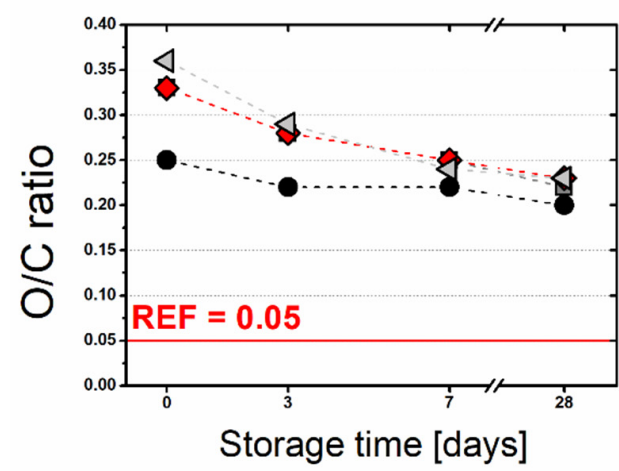

b) VDBD

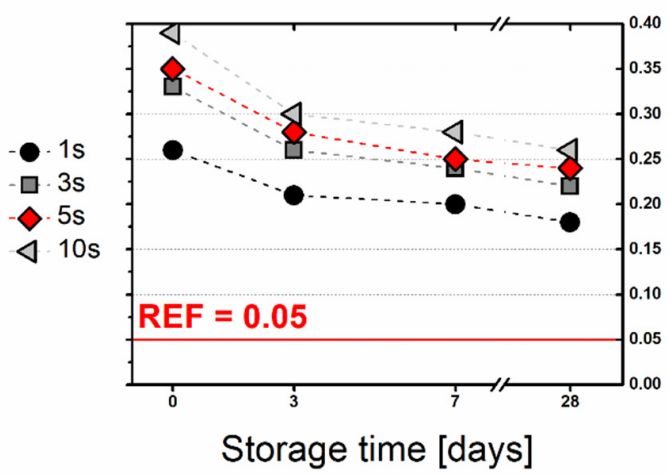

Figure 7. Development of the O/C ratio during the storage of BOPP foils under laboratory conditions: $\mathrm{O} / \mathrm{C}$ ratio plotted against the storage time for (a) DCSBD and (b) VDBD for all plasma treatment conditions.

\section{Conclusions}

In the present work, we investigated the impact of VDBD and DCSBD plasma treatment on the surface characteristics of BOPP foil. Considering the surface morphology, the filamentary plasma produced by VDBD had a more destructive effect than the diffuse plasma generated by DCSBD. The smooth nature of BOPP foil remained unchanged during the first $3 \mathrm{~s}$ of DCSBD plasma treatment, whereas VDBD caused surface roughening after $1 \mathrm{~s}$ of treatment. Moreover, plasma exposure time higher than $1 \mathrm{~s}$ in the case of VDBD induced undesirable haze. Although DCSBD treatment at 5-10 s resulted in the formation of droplet-like structures, the foil remained transparent. Improvement in wettability was achieved for both plasma sources. However, exposure to VDBD plasma longer than $3 \mathrm{~s}$ led to a WCA increase perhaps due to surface roughening. Increased roughness after VDBD treatment also contributed to enhanced adhesion, where longer treatment time (5-10 s) caused an increase in peel force. Nevertheless, adhesion improved after $1 \mathrm{~s}$ of treatment by both plasma sources, indicating the direct relation of BOPP adhesive properties with the formation of polar functional groups. Surface oxidation was achieved after $1 \mathrm{~s}$ of plasma exposure and increased with the plasma treatment time. Observed oxygen contents were comparable for both plasma sources reflecting the similar level of surface oxidation for diffuse and filamentary plasma. Considering the WCA values as well as the $\mathrm{O} / \mathrm{C}$ ratio development during the month of storage, the acquired surface properties slightly recovered without achieving initial characteristics. BOPP foil remained hydrophilic after the treatment by both plasma sources; however, the WCA after a month in the case of DCSBD were lower than for VDBD treated samples. These data show that BOPP foil requires treatment by diffuse plasma of DCSBD longer than $1 \mathrm{~s}$ for sufficient surface oxidation. BOPP treated at $3 \mathrm{~s}$ by both plasma sources achieved similar surface activation. However, considering the surface morphology, VDBD treatment longer than $3 \mathrm{~s}$ induced structural changes in the microscale which led to optical haze, whereas DCSBD treatment retained the transparency of the foil. Although these results prove a similar efficiency of diffuse and 
filamentary plasma on BOPP surface activation, it supports the high potential of DCSBD technology to be part of industrial systems as it is gentler to sensitive polymeric surfaces.

Author Contributions: D.K. designed the study; J.K., P.Š. and M.F. performed plasma treatment optimization and conducted all plasma treatments as well as WCA/SFE and peel force measurements; P.Š. evaluated the XPS data; Z.K.T. performed SEM imaging and AFM measurements; P.Š. and Z.K.T. interpreted data, wrote and revised the manuscript; D.K. had oversight of the whole experiment and contributed to the revision of the manuscript. All authors have read and agreed to the published version of the manuscript.

Funding: This research has been supported by the project " $R \& D$ centre for plasma and nanotechnology surface modifications (CEPLANT)", LM2018097 funded by the Ministry of Education, Youth and Sports.

Institutional Review Board Statement: Not applicable.

Informed Consent Statement: Not applicable.

Data Availability Statement: Not applicable.

Acknowledgments: We acknowledge CzechNanoLab Research Infrastructure supported by MEYS CR (LM2018110) for XPS measurements.

Conflicts of Interest: The authors declare no conflict of interest.

\section{References}

1. Calafut, T. Polypropylene Films. In Plastic Films in Food Packaging; Elsevier: Amsterdam, The Netherlands, 1998; pp. 17-20.

2. Ščetar, M.; Kurek, M.; Režek Jambrak, A.; Debeaufort, F.; Galić, K. Effect of high power ultrasound on physical-chemical properties of polypropylene films aimed for food packaging: Structure and surface features. Polym. Bull. 2019, 76, 1007-1021. [CrossRef]

3. Gull, A.; Prasad, K.; Kumar, P. Quality Changes in Functional Pasta During Storage in Two Different Packaging Materials: LDPE and BOPP. J. Food Process. Preserv. 2017, 41, 1-7. [CrossRef]

4. Huan, T.D.; Boggs, S.; Teyssedre, G.; Laurent, C.; Cakmak, M.; Kumar, S.; Ramprasad, R. Advanced polymeric dielectrics for high energy density applications. Prog. Mater. Sci. 2016, 83, 236-269. [CrossRef]

5. Guimond, S.; Radu, I.; Czeremuszkin, G.; Carlsson, D.J.; Wertheimer, M.R. Biaxially Oriented Polypropylene (BOPP) Surface Modification by Nitrogen Atmospheric Pressure Glow Discharge (APGD) and by Air Corona. Plasmas Polym. 2002, 7, 71-88. [CrossRef]

6. Novák, I.; Florián, Š. Investigation of long-term hydrophobic recovery of plasma modified polypropylene. J. Mater. Sci. 2004, 39, 2033-2036. [CrossRef]

7. S Štěpánová, V.; Šrámková, P.; Sihelník, S.; Stupavská, M.; Jurmanová, J.; Kováčik, D. The effect of ambient air plasma generated by coplanar and volume dielectric barrier discharge on the surface characteristics of polyamide foils. Vacuum 2021, $183,109887$. [CrossRef]

8. Galmiz, O.; Kelar Tučeková, Z.; Kelar, J.; Zemánek, M.; Stupavská, M.; Kováčik, D.; Černák, M. Effect of atmospheric pressure plasma on surface modification of paper. AIP Adv. 2019, 9, 105013. [CrossRef]

9. Černák, M.; Kováčik, D.; Ráhel', J.; St’ahel, P.; Zahoranová, A.; Kubincová, J.; Tóth, A.; Černáková, L. Generation of a high-density highly non-equilibrium air plasma for high-speed large-area flat surface processing. Plasma Phys. Control. Fusion 2011, 53, 124031. [CrossRef]

10. Kormunda, M.; Homola, T.; Matoušek, J.; Kováčik, D.; Černák, M.; Pavlik, J. Surface analysis of poly(ethylene naphthalate) (PEN) films treated at atmospheric pressure using diffuse coplanar surface barrier discharge in air and in nitrogen. Polym. Degrad. Stab. 2012, 97, 547-553. [CrossRef]

11. Shekargoftar, M.; Kelar, J.; Krumpolec, R.; Jurmanová, J.; Homola, T. A Comparison of the Effects of Ambient Air Plasma Generated by Volume and by Coplanar DBDs on the Surfaces of PP/Al/PET Laminated Foil. IEEE Trans. Plasma Sci. 2018, 46, 3653-3661. [CrossRef]

12. Hergelová, B.; Zahoranová, A.; Kováčik, D.; Stupavská, M.; Černák, M. Polylactic acid surface activation by atmospheric pressure dielectric barrier discharge plasma. Open Chem. 2015, 13, 564-569. [CrossRef]

13. Kelar, J.; Shekargoftar, M.; Krumpolec, R.; Homola, T. Activation of polycarbonate (PC) surfaces by atmospheric pressure plasma in ambient air. Polym. Test. 2018, 67, 428-434. [CrossRef]

14. Homola, T.; Matoušek, J.; Hergelová, B.; Kormunda, M.; Wu, L.Y.L.; Černák, M. Activation of poly(methyl methacrylate) surfaces by atmospheric pressure plasma. Polym. Degrad. Stab. 2012, 97, 886-892. [CrossRef]

15. Saranko, A.; Szakal, Z.; Kalacska, G.; Samyn, P.; Sukumaran, J.; Klebert, S.; Karoly, Z. Adhesion and sliding tribological properties of polyolefins treated by diffuse coplanar surface barrier discharges. Express Polym. Lett. 2018, 12, 972-985. [CrossRef]

16. Janík, R.; Kohutiar, M.; Pajtášová, M.; Dubec, A.; Pagáčová, J.; Šulcová, J. The impact of DCSBD plasma discharge on polypropylene. IOP Conf. Ser. Mater. Sci. Eng. 2020, 776, 012090. [CrossRef] 
17. Kohutiar, M.; Janík, R.; Pajtášová, M.; Ondrušová, D.; Labaj, I.; Zvoláneková Mezencevová, V. Study of structural changes in thermoplastics using dynamic mechanical analysis. IOP Conf. Ser. Mater. Sci. Eng. 2020, 776, 012092. [CrossRef]

18. Oravcová, A.; Hudec, I. The influence of atmospheric pressure plasma treatment on surface properties of polypropylene films. Acta Chim. Slovaca 2010, 3, 57-62.

19. Owens, D.K.; Wendt, R.C. Estimation of the surface free energy of polymers. J. Appl. Polym. Sci. 1969, 13, 1741-1747. [CrossRef]

20. Wokovich, A.M.; Brown, S.A.; McMaster, F.J.; Doub, W.H.; Cai, B.; Sadrieh, N.; Mei, L.C.; Machado, S.; Shen, M.; Buhse, L.F. Evaluation of substrates for $90^{\circ}$ peel adhesion-A collaborative study: I. Medical tapes. J. Biomed. Mater. Res. Part B Appl. Biomater. 2008, 87, 105-113. [CrossRef]

21. McGuiggan, P.M.; Chiche, A.; Filliben, J.J.; Yarusso, D.J. Peel of an adhesive tape from a temperature-gradient surface. Int. J. Adhes. Adhes. 2008, 28, 185-191. [CrossRef]

22. Junkar, I.; Cvelbar, U.; Vesel, A.; Hauptman, N.; Mozetič, M. The role of crystallinity on polymer interaction with oxygen plasma. Plasma Process. Polym. 2009, 6, 667-675. [CrossRef]

23. Strobel, M.; Strobel, J.M.; Jones, V.; Lechuga, H.; Lyons, C.S. Effect on wettability of the topography and oxidation state of biaxially oriented poly(propylene) film. J. Adhes. Sci. Technol. 2019, 33, 1644-1657. [CrossRef]

24. Chen, W.X.; Yu, J.S.; Chen, G.L.; Qiu, X.P.; Hu, W.; Bai, H.Y.; Shao, J.Z. Development of a novel protocol for the permanent hydrophilic modification of a BOPP film for high quality printing with water-based ink. RSC Adv. 2015, 5, 87963-87970. [CrossRef]

25. Darvish, F.; Mostofi Sarkari, N.; Khani, M.; Eslami, E.; Shokri, B.; Mohseni, M.; Ebrahimi, M.; Alizadeh, M.; Dee, C.F. Direct plasma treatment approach based on non-thermal gliding arc for surface modification of biaxially-oriented polypropylene with post-exposure hydrophilicity improvement and minus aging effects. Appl. Surf. Sci. 2020, 509, 144815. [CrossRef]

26. Wang, C.; He, X. Polypropylene surface modification model in atmospheric pressure dielectric barrier discharge. Surf. Coat. Technol. 2006, 201, 3377-3384. [CrossRef]

27. Gim, S.; Lee, I.; Park, J.Y.; Lee, J.L. Spontaneously Embedded Scattering Structures in a Flexible Substrate for Light Extraction. Small 2017, 13, 1-8. [CrossRef] [PubMed]

28. Cortese, B.; Morgan, H. Controlling the Wettability of Hierarchically Structured Thermoplastics. Langmuir 2012, 28, 896-904. [CrossRef] [PubMed]

29. Dorai, R.; Kushner, M.J. A model for plasma modification of polypropylene using atmospheric pressure discharges. J. Phys. D Appl. Phys. 2003, 36, 666-685. [CrossRef]

30. Borcia, G.; Anderson, C.A.; Brown, N.M.D. The surface oxidation of selected polymers using an atmospheric pressure air dielectric barrier discharge: Part I. Appl. Surf. Sci. 2004, 221, 203-214. [CrossRef]

31. Hanusová, J.; Kováčik, D.; Stupavská, M.; Černák, M.; Novák, I. Atmospheric pressure plasma treatment of polyamide-12 foils. Open Chem. 2015, 13, 382-388. [CrossRef]

32. Bhat, N.V.; Upadhyay, D.J. Plasma-induced surface modification and adhesion enhancement of polypropylene surface. J. Appl. Polym. Sci. 2002, 86, 925-936. [CrossRef]

33. Mirabedini, S.M.; Arabi, H.; Salem, A.; Asiaban, S. Effect of low-pressure $\mathrm{O}_{2}$ and Ar plasma treatments on the wettability and morphology of biaxial-oriented polypropylene (BOPP) film. Prog. Org. Coat. 2007, 60, 105-111. [CrossRef]

34. Morent, R.; De Geyter, N.; Leys, C.; Gengembre, L.; Payen, E. Comparison between XPS- And FTIR-analysis of plasma-treated polypropylene film surfaces. Surf. Interface Anal. 2008, 40, 597-600. [CrossRef]

35. Navaneetha Pandiyaraj, K.; Selvarajan, V.; Deshmukh, R.R.; Gao, C. Adhesive properties of polypropylene (PP) and polyethylene terephthalate (PET) film surfaces treated by DC glow discharge plasma. Vacuum 2008, 83, 332-339. [CrossRef]

36. Leroux, F.; Campagne, C.; Perwuelz, A.; Gengembre, L. Polypropylene film chemical and physical modifications by dielectric barrier discharge plasma treatment at atmospheric pressure. J. Colloid Interface Sci. 2008, 328, 412-420. [CrossRef] [PubMed]

37. Ding, L.; Zhang, X.; Wang, Y. Study on the Behavior of BOPP Film Treated by Corona Discharge. Coatings 2020, 10, 1195. [CrossRef] 